\title{
Method of the Determining the Dynamic Strength of the Liquid
}

\author{
Alexander U. Radzyuk and Elena B. Istyagina* \\ Siberian Federal University \\ 79 Svobodny, Krasnoyarsk, 660041, Russia
}

Received 26.04.2016, received in revised form 30.07.2016, accepted 02.01.2017

This article discusses the dynamic strength of the liquids. The laboratory setup was created to solve this problem. The method of determining the intensity of cavitation in dependence from of the volume of the resultant gas-vapor mixture was presented. During the experiments was to study the behavior of different liquids depending on the type of fluid and from the amount of dissolved air in it.

Keywords: dynamic strength of the liquids, cavitation, gas-vapor mixture.

Citation: Radzyuk A.U., Istyagina E.B. Method of the determining the dynamic strength of the liquid, J. Sib. Fed. Univ. Eng. technol., 2017, 10(1), 44-47. DOI: 10.17516/1999-494X-2017-10-1-44-47.

\section{Метод определения}

\section{динамической прочности жидкости}

А.Ю. Радзюк, Е.Б. Истягина

Сибирский федеральный университет Россия, 660041, Красноярск, пр. Свободныий, 79

\begin{abstract}
В данной статье рассматривается экспериментальный метод определения динамической прочности жидкостей. Для решения поставленной задачи была создана лабораторная установка. Представлен метод определения интенсивности кавитации в зависимости от объема результирующей парогазовой смеси. В ходе экспериментов было изучение поведение различных жидкостей в зависимости от типа жидкости и количества растворенного в ней воздуха.
\end{abstract}

Ключевые слова: динамическая прочность жидкости, давление насыщения, парогазовая смесь.

Динамическая (разрывная) прочность капельной жидкости - это свойство жидкости оставаться сплошной средой под действием внешних сил, приводящих к сдвиговым напряжениям

C) Siberian Federal University. All rights reserved

* Corresponding author E-mail address: d327@mail.ru,tim.484@mail.ru 
в слоях жидкости. Это свойство связано с явлением кавитации, под которым следует понимать нарушение динамической прочности, т.е. разрыва жидкости, проявляющегося в образовании каверн.

Для исследования динамической прочности предлагается использовать экспериментальный подход. Основным элементом измерительной установки служит камера с подвижным поршнем (шприц), соединенная трубкой с питающим сосудом (колбой), заполненным исследуемой жидкостью (рис. 1).

Под действием внешней силы $F$ создается давление $p=F / S_{l}$ и поршень перемещается, перекачивая некий объем жидкости $\Delta V$ из основного цилиндра. Изменение объема жидкости в сосуде с течением времени можно описать зависимостью

$$
V_{2}\left(\tau_{2}\right)=V_{2}\left(\tau_{1}\right)+\left(V_{1}\left(\tau_{1}\right)-V_{1}\left(\tau_{2}\right)\right)+V_{П Г}\left(\tau_{2}\right),
$$

где $V_{\text {пг }}$ - объем парогазовой смеси, образующейся в результате резкого изменения давления под действием внешней силы (рис. 2).

Объем этой смеси характеризует кавитационную прочность жидкости, а также интенсив-

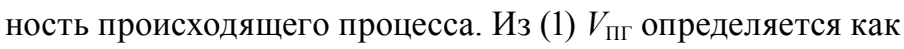

$$
V_{\text {ПГ }}\left(\tau_{2}\right)=\left[V_{2}\left(\tau_{2}\right)-V_{2}\left(\tau_{1}\right)\right]-\left[V_{1}\left(\tau_{1}\right)-V_{1}\left(\tau_{2}\right)\right],
$$

где выражение в последней квадратной скобке является количеством перешедшей из сосуда

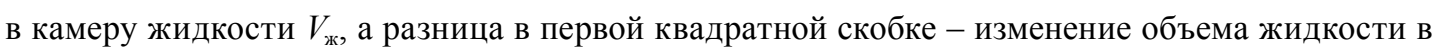
камере $\Delta V_{2}$, т.е.

$$
V_{\Pi \Gamma}=\Delta V_{2}-\Delta V_{1}
$$

Величина объема парогазовой смеси зависит как от разницы давлений насыщения растворенных в жидкости паров и давления, создаваемого внешней силой, так и от свойств и состояния самой жидкости.

Средняя по сечению скорость движения жидкости в трубке такова:

$$
\omega=\frac{V_{2}\left(\tau_{2}\right)-V_{2}\left(\tau_{1}\right)}{S_{2}\left(\tau_{2}-\tau_{1}\right)} .
$$

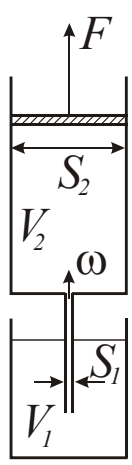

Рис. 1. Схема рабочего элемента лабораторной установки

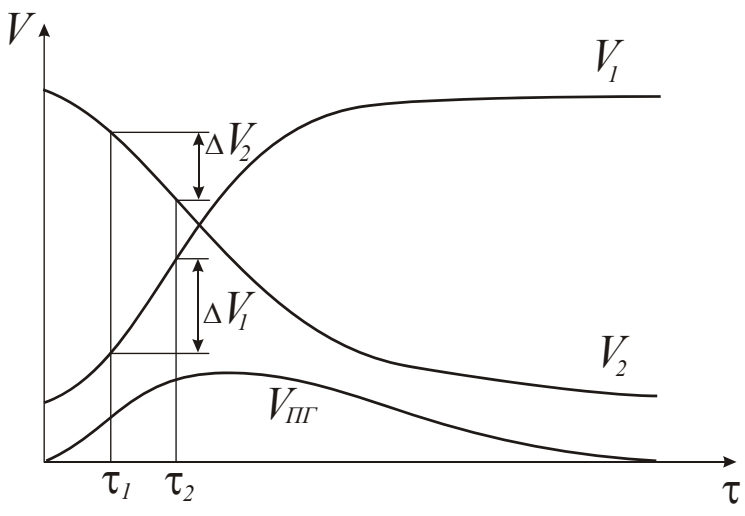

Рис. 2. Изменение величин во времени 
Для определения динамической прочности жидкости разработана экспериментальная установка (рис. 3), представляющая собой рычажные коромысловые весы, на одной стороне которых закреплен поршень шприца, а на второй - чашка с грузами. Разряжение в камере создавалось поршнем, совершающим работу под воздействием груза. Игла шприца опущена в колбу с испытуемой жидкостью. Для исключения погрешности при отпускании груза чашка с грузами освобождается с помощью электрозамка.

В условиях эксперимента предлагается использовать замкнутую камеру, в которой жидкость ограничена боковой поверхностью, дном сосуда и поршнем со штоком (см. рис. 1). Кавитационная камера представляет собой стеклянный цилиндр (шприц), через прозрачные стенки которого производится визуальное наблюдение за происходящими процессами.

Физические условия, созданные в экспериментальной установке, гарантировали наличие режимов течения, характеризующихся нарушением сплошности потока.

Вакуум в кавитационной камере создавался поршневым насосом, на поршень которого осуществлялось необходимое силовое воздействие с помощью груза различной массы. Динамика происходящих процессов фиксировалась цифровой видеосъемкой и анализировалась на компьютере. На рис. 4 приведена одна из кинограмм происходящего процесса.

По изменению положения поршня в кавитационной камере и уменьшению уровня жидкости в питающем сосуде вычислялись изменения объемов, прочность оценивалась по величине разности между этими значениями.

Для отработки техники измерений опыты проведены с водой и нефтью Юрубченского месторождения. Результаты исследований отражены на рис. 5 и 6.

Полученные данные демонстрируют наличие разницы между объемами верхней камеры $V_{2}$ и нижней, $V_{1}$. Разница между полученными объемами соответствует $V_{\text {пг }}$ - объему парогазовой смеси, образующейся в результате резкого изменения давления под действием силы, приложенной к поршню. Таким образом, величина внешней силы может быть связана с нарушением сплошности, а значит, с процессом кавитации.

Предложенный метод позволяет вычислить скорость движения жидкости по каналу, давления в обоих сосудах, зафиксировать момент начала разрыва жидкости и с достаточной точностью получить зависимости, характеризующие интенсивность гидродинамической кавитации.

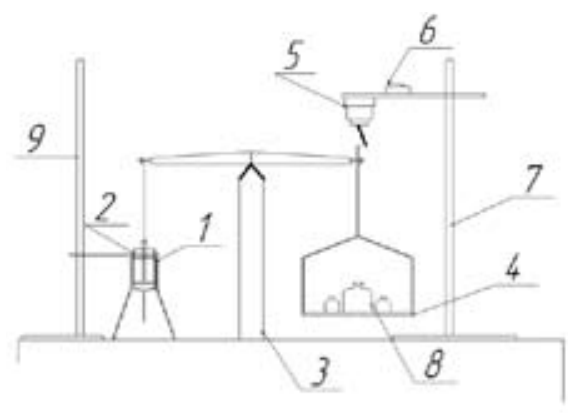

Рис. 3. Лабораторный стенд для исследования прочностных свойств жидких сред: 1 - емкость с жидкостью; 2 - шприц; 3 - лабораторные весы; 4 - подставка; 5 - электрозамок; 6 - выключатель; 7, 9 - штатив; 8 - грузы 


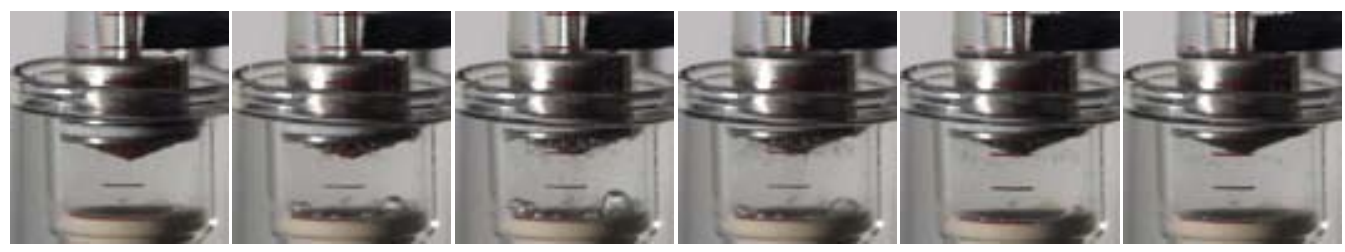

Рис. 4. Образование и схлопывание парогазовых каверн

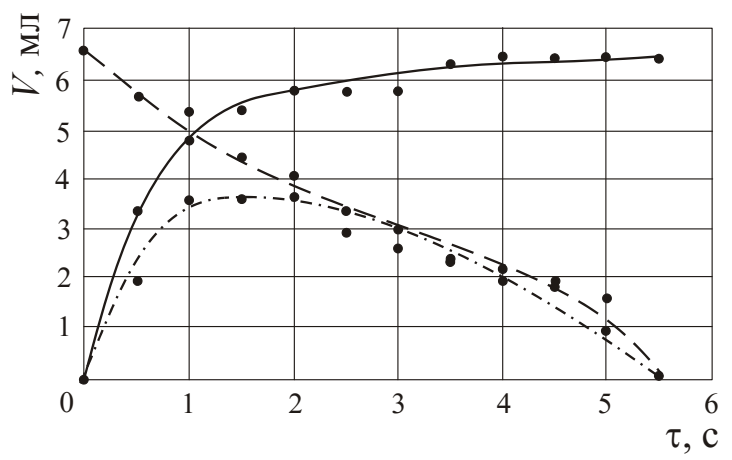

Рис. 5. Изменение объемов газожидкостной фазы в водопроводной воде с течением времени: -- $-V_{l}$; $---V_{2} ;-\cdot-\cdot-\Delta V$

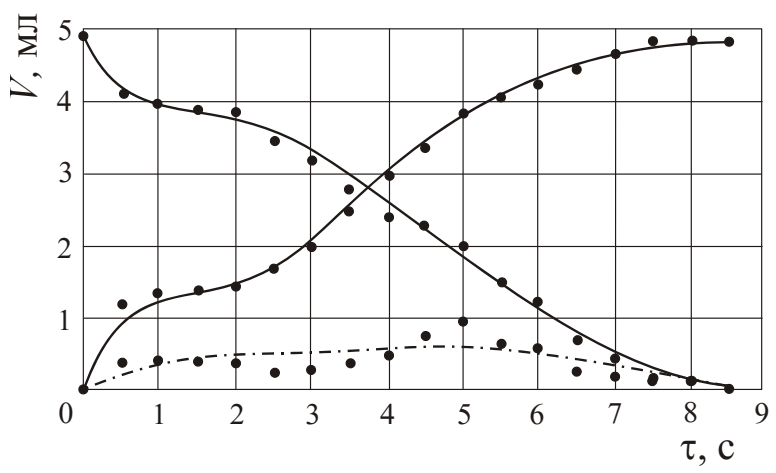

Рис. 6. Изменение объемов газожидкостной фазы в нефти с течением времени: $---V_{l} ;---V_{2} ;-\cdot-\cdot-\Delta V$

\section{Список литературы}

[1] Пильгунов В.Н. Исследование разрывной прочности минерального масла. Наука и образование: научное издание МГТУ им. Н.Э. Баумана, 2012, 5, 15 [Pilgunov V.H. Investigation of tensile strength of mineral oil. Science and education: scientific edition, 2012, 5, 15 (in Russian)]

[2] Исаков А.Я., Исаков А.А. Кавитащия в перемешивающих устройствах. ПетропавловскКамчатский: КамчатГТУ, 2006. 206 с. [Isakov A.Y., Isakov A.A. Cavitation mixing devices. Petropavlovsk-Kamchatskiy, KamcatGTU, 2006. 206 p. (in Russian)] 